O. Engvold (ed.), Transactions of the International Astronomical Union, Vol. XXVB.

(C)2007 IAU. Printed in the United States of America

\title{
DIVISION III: PLANETARY SYSTEMS SCIENCES
} (SCIENCES DES SYSTEMES PLANETAIRES)

PRESIDENT: Mikhail Marov

BOARD: M.F. A'Hearn, W.J. Baggaley, E.L.G. Bowell, S. Bowyer, D.P. Cruikshank, C. de Bergh, H.U. Keller, P. Lamy, V. Porubcan, J. Watanabe, I.P. Williams, V. Zappalà

\author{
Commission 15: Physical Studies of Comets and Minor Planets \\ Commission 16: Physical Studies of Planets and Satellites \\ Commission 20: Positions and Motions of Minor Planets, Comets, \\ and Satellites \\ Commission 21: Light of the Night Sky \\ Commission 22: Meteors and Interplanetary Dust \\ Commission 51: Bioastronomy \\ Working Group: Small Body Nomenclature \\ Working Group: Planetary System Nomenclature \\ Working Group: Near Earth Objects
}

\section{Introduction}

Since the business of Division III is conducted primarily in its commissions and working groups, the division held only a single session during the GA, during which the division considered the reports of the various working groups, elected officers, and discussed reorganization of the division. Approximately 40 members of the division attended the session.

\section{Nomenclature}

The chairpersons of the Committee on Small Body Nomenclature (CSBN) and of the Working Group on Planetary System Nomenclature (WGPSN) presented reports on their naming activities during the triennium. The two groups had agreed to transfer the naming of satellites of asteroids and other small bodies from the WGPSN to the CSBN and this was endorsed by the division.

The attendees were referred to the web pages of the CSBN for the lists of 700 comets and 3105 minor planets named during 2000-2002. These web pages can be found by linking down from the pages of the IAU at http://www.iau.org/. They currently reside at http://www.ss.astro.umd.edu/IAU/csbn/. The names were endorsed by acclamation. The CSBN brought forward an appeal of a name that had been rejected by the CSBN, that of Hahneman. After considerable discussion, the rejection by the CSBN of this name was endorsed by the division by a vote of 25 to 15 . The division endorsed the proposed membership for the next triennium. Further details are in the report of the CSBN. 
The WGPSN also reported on the names assigned to 35 satellites and to 216 surface features during 2000-2002, the names of which are on the web pages of the WGPSN, together with the Planetary Gazeteer, at the U. S. Geological Survey. These web pages can also be found by linking down from the pages of the IAU. They currently reside at http://planetarynames.wr.usgs.gov/. These names were also officially adopted by the division. The division endorsed the proposed membership for the next triennium. Further details are in the report of the WGPSN.

\section{Other Working Groups}

The Working Group on Near Earth Objects (WGNEO) and the Working Group on Extrasolar Planets (WGESP) presented reports on their activities during the previous triennium. The report of the WGNEO is included in these transactions and details are there, but the WGESP did not meet during the General Assembly. The WGESP's principal activities were related to the definition of what constitutes a planet. A planet must be orbiting a star and must satisfy the constraint against deuterium burning. As a practical matter, the constraint is set as $M \times \sin (i)<10 M_{J}$, whereas the theoretical limit for deuterium burning is $13 M_{J}$. Objects between $13 M_{J}$ and $0.08 M_{\text {sun }}$ will be known as brown dwarfs, while free-floating objects, i.e., those not bound to a star, with $M<10 M_{J}$ will be known as sub-brown-dwarfs. Using the criterion of acceptance for publication of the report on the discovery, there are now 95 extra-solar planets recognized, with more expected in the near future. The WGESP has not considered the question of a minimum mass for a planet, that being still an issue within our own solar system but not yet an issue for extra-solar planets. The membership of both working groups for the coming triennium was approved by the division (that of the WGESP is unchanged from the previous triennium).

It was reported that the Working Group on Rotational and Cartographic Coordinates, heretofore a working group of Division I, was seeking joint sponsorship by Division III. It was noted that a large fraction of the membership of the working group consisted of individuals who were members of Division III but not of Division I. Division I agreed to the joint sponsorship. There was some discussion of the awkwardness of jointlysponsored working groups, since the chairman of the working group might have doubled reporting duties and might not know which divisional route to follow for various issues. After this discussion, which did not resolve the awkwardness, the division agreed that it would jointly sponsor the Working Group on Rotational and Cartographic Coordinates.

It was also reported that the IAU Executive Committee desired to have the previous Minor Planet Center Advisory Committee, which reported to Commission 20, become simply the Minor Planet Center Committee and report at a higher level, specifically to the IAU General Secretary through Division III (and not through a commission). The reason for the change is the fact that there is a contractual and financial agreement between the IAU, i.e., the Executive Committee, and the Minor Planet Center. There was some discussion of the role of this committee, specifically whether it was advisory to the MPC or advisory to the IAU (clarified as being the latter). The discussion soon expanded to a discussion of the Terms of Reference for the Minor Planet Center and the contract between the IAU and the Minor Planet Center, matters that had been under discussion within the IAU Executive Committee. The discussion was then ended because most members of the division had not seen copies of either the Terms of Reference or the contract and, in any case, the contract was held by the IAU, not by Division III. By agreement between the divisional officers and the IAU Executive Committee, the new Minor Planet Center Committee will report as indicated above. Because these decisions were taken at a late date during the General Assembly, the membership of the committee was left unspecified and members will be appointed during the coming triennium. 


\section{Elections}

Election procedures are changed under the new bylaws of the IAU and the elections at this General Assembly followed a mixture of old and new rules. The division endorsed the election of the presidents and vice-presidents of its six commissions as proposed by those commissions.

The division endorsed the election of I. P. Williams, previously nominated by the outgoing president to the EC, as the new president. A ballot of those members of the divisional Organizing Committee (OC) present in Sydney led to the election of E. L. G. Bowell as the new vice-president. A slate of candidates for the OC was presented to the division by the acting president. Additional nominations were accepted from the floor. There was considerable discussion of the many issues facing the division in the coming triennium and thus of the need for various kinds of expertise on the OC. There was a consensus that the division needed an $\mathrm{OC}$ rather larger than that specified as normal by the IAU. After much discussion, the division elected M.F. A'Hearn, A.P. Boss, E.L.G. Bowell, D.P. Cruikshank, A.-C. Levasseur-Regourd, M. Marov, D. Morrison, and C. Tinney to serve on the OC together with the new presidents of all the commissions in the division. The division urged the officers to make the case to the IAU for the larger number of members, based on the breadth of important issues addressed by the division. The incoming president appointed G. Consolmagno as secretary of the division.

\section{Divisional Organization}

The incoming president led a discussion of the future of the division. He noted that the division consists of everyone in the IAU interested in planetary sciences and that the commissions represent the way the division organizes itself to get scientific work accomplished. He proposed that the division conduct an open, electronic discussion of how it could be most efficiently organized, ignoring all existing structures. He expressed his hope that the discussion could last a year or so and that the remainder of the triennium could then be devoted to preparing a plan of organization that would be presented at the next GA. The reorganization itself might not officially take place until the following GA, i.e., in 2009.

Michael F. A'Hearn

Acting President of the Division for

Mikhail Marov

President of the Division 